\title{
Fabrication of a Porous Slippery Icephobic Surface and Effect of Lubricant Viscosity on Anti-Icing Properties and Durability
}

\author{
Guoyong Liu ${ }^{1}$, Yuan Yuan ${ }^{2}{ }^{*}$, Ruijin Liao ${ }^{1}$, Liang Wang ${ }^{2}$ and Xue Gao ${ }^{2}$ \\ 1 State Key Laboratory of Power Transmission Equipment \& System Security and New Technology, \\ Chongqing University, Chongqing 400044, China; GuoyongLiu@cqu.edu.cn (G.L.); rjliao@cqu.edu.cn (R.L.) \\ 2 College of Materials Science and Engineering, Chongqing University, Chongqing 400044, China; \\ wliang0306@126.com (L.W.); gaoxue@cqu.edu.cn (X.G.) \\ * Correspondence: yuany@cqu.edu.cn
}

Received: 30 August 2020; Accepted: 16 September 2020; Published: 18 September 2020

\begin{abstract}
A breakdown caused by the icing of power generation infrastructure is one of the serious disasters occurring in the power system. Slippery lubricant-infused porous surfaces (SLIPSs), whose ice adhesion strength is extremely low, have a promising application in the anti-icing field. In the present study, we fabricated SLIPSs with low ice adhesion strength by infusing silicone oil into an anodic aluminum oxide (AAO) substrate. In addition, the effects of the viscosity of silicone oil on the anti-icing properties and durability of the SLIPSs were investigated. The results show that a lower viscosity silicone oil brings about more slippery surfaces and lower ice adhesion strength. The ice adhesion strength was reduced by $99.3 \%$ in comparison with the bare Al alloy. However, low-viscosity silicone oil has worse de-icing resistance and heat resistance. Additionally, the porous films filled with low-viscosity silicone oil possess a better self-healing property after icing/de-icing cycles and followed by exposure to the atmosphere. When the viscosity of silicone oil is $50 \mathrm{mPa} \cdot \mathrm{s}$, the SLIPSs exhibit the best durability for anti-icing. Even after 21 de-icing tests or $168 \mathrm{~h}$ of heating at $90{ }^{\circ} \mathrm{C}$, the ice adhesion strength still remains below $10 \%$ compared with that of bare Al. This work provides some useful advice for the design and fabrication of anti-icing SLIPSs.
\end{abstract}

Keywords: slippery lubricant-infused porous surfaces; ice adhesion; anodization; anti-icing; durability; viscosity

\section{Introduction}

The accumulation of ice on aluminum conductors can cause disastrous problems, such as line breaking and tower collapse, due to the increased weight overloading the structures [1,2]. Over the past few decades, icing problems have received much attention in the fields of science and engineering. Conventional strategies to solve icing problems included removing ice from conductors before failure occurs, such as overcurrent ice-melting and mechanical de-icing [3,4]. However, these methods have low efficiency and high energy consumption and can even damage the equipment $[5,6]$. Materials that can prevent ice accumulation without energy input have been widely studied $[7,8]$.

Inspired by the idea of the lotus effect, superhydrophobic surfaces have shown promise as anti-icing materials because the cooled water could roll away from the surfaces $[9,10]$. However, recent reports have indicated that superhydrophobicity would be lost if water vapor condensed on the micro-nanostructure of superhydrophobic surfaces under conditions of low temperature with high humidity [11]. Additionally, the mechanical interlocking effect between the ice and the micro-nanostructure of superhydrophobic surfaces has led to an increase in the ice adhesion strength $[12,13]$. 
Low ice adhesion materials are a hopeful anti-icing strategy where the ice automatically detaches from the surface by gravity $[14,15]$. Recently, slippery lubricant-infused porous surfaces (SLIPSs) were considered as promising anti-icing materials, which were inspired by Nepenthes pitcher plants $[8,16]$. SLIPSs have excess lubricant infused into the pores, resulting in the liquid layer on the top. Researchers have prepared many SLIPS materials because of their potential applications, such as self-cleaning [17], anti-corrosion [18,19], anti-frosting [20,21] and anti-icing [19,22] features. Additionally, the lubricant layer on the SLIPS displays slippery properties leading to a minimized adhesion between the surface and the ice [23,24]. A lubricant has mobility, and thus can allow self-healing properties [18,25]. However, the liquid lubricant may be depleted because of evaporation or the de-icing process, which causes ice adhesion values to increase $[16,26]$. SLIPSs can be obtained by infusing a lubricant into a porous structure. The porous structure of SLIPSs has been prepared in several ways, such as chemical etching [24], porous polymer, self-assembly, and chemical deposition [20]. Anodic oxidation is a common approach to improving the abrasion resistance of an aluminum surface. The pores of the anodic aluminum oxide (AAO) layer are beneficial to absorb and retain the lubricant within the pores. Moreover, anodic oxidation is suitable for a complicated structure, such as aluminum-conductor steel-reinforced cable (ACSR). The lubricant has a significant effect on the performance of the SLIPS [27,28]. For the lubricant, the following criteria are essential [8,29]: (1) the infused lubricant should possess durability under severe conditions; (2) the infused lubricant is immiscible with water; and (3) the infused lubricant can be easily deposited onto a porous structure. The relationships between ice adhesion and lubricant characteristics including viscosity, density, and surface tension were studied [30]. The viscosity of the lubricant affects the efficiency of the infusion and the depletion of the lubricant [31]. The critical self-healing thickness of the SLIPS increases with the increase in silicone oil viscosity [28]. However, the effect of lubricant viscosity on the anti-icing properties and durability still requires further study.

Here, we successfully fabricated SLIPSs with low ice adhesion strength by infusing different viscosities of silicone oil into AAO. The infusion of silicone oils into a porous structure was examined using a scanning electron microscope (SEM). The effects of the viscosity of the silicone oil on the anti-icing properties were studied by measuring the ice adhesion strength. To evaluate durability, we performed cyclic icing/de-icing tests and thermal tests on SLIPS samples. The relationships between the lubricant viscosity and durability of the SLIPSs were obtained. The effects of silicone oil viscosity on the self-healing performance of SLIPSs after icing/de-icing tests were studied as well.

\section{Materials and Methods}

\subsection{Materials}

Aluminum alloy plates (6061-T6) were purchased from Dongguan Chaomei Aluminum Products Co., Ltd. (Dongguan, China) and cut into $30 \mathrm{~mm} \times 30 \mathrm{~mm} \times 1 \mathrm{~mm}$ pieces. Ethanol (99.7 wt.\%), sodium hydroxide $(\mathrm{NaOH})$, and oxalic acids $\left(\mathrm{H}_{2} \mathrm{C}_{2} \mathrm{O}_{4}, 99\right.$ wt.\%) were purchased from Chongqing Huadong Chemical Co. Ltd. (Chongqing, China). Hexadecyltrimethoxysilane (HDTMS) and silicone oil (viscosity 10, 20, 50, 100, $200 \mathrm{mPa} \cdot \mathrm{s}$ ) were purchased from Aladdin (Shanghai, China).

\subsection{Preparation of SLIPSS}

Figure 1 illustrates the method of preparing the SLIPS. The Al alloy plate was first washed ultrasonically with deionized water and then by ethanol, and finally dried. Then, the Al plates were immersed in a $\mathrm{NaOH}$ solution to remove the oxide layer. After removal of the oxide layer, the plates were ultrasonically cleaned in deionized water. Afterwards, the anodization process was implemented so as to generate nanopores on the surface. The prepared $\mathrm{Al}$ surface and 304 stainless steel were taken as anode and cathode, respectively. The anodization was conducted by applying $0.16 \mathrm{~A} / \mathrm{cm}^{2}$ in $0.15 \mathrm{M}$ oxalic acids at $20^{\circ} \mathrm{C}$ for $10 \mathrm{~min}$. AAO was modified by HDTMS to improve the hydrophobicity and compatibility. Specifically, the anodized samples were immersed in an ethanol solution of $2 \mathrm{wt.} \%$ 
HDTMS for $30 \mathrm{~min}$ and then dried at $90^{\circ} \mathrm{C}$ for $1 \mathrm{~h}$. Subsequently, to obtain the SLIPS, the surface was immersed in the silicone oil at $80^{\circ} \mathrm{C}$ for $24 \mathrm{~h}$ under vacuum. A homogeneous oil layer was obtained on the surface.

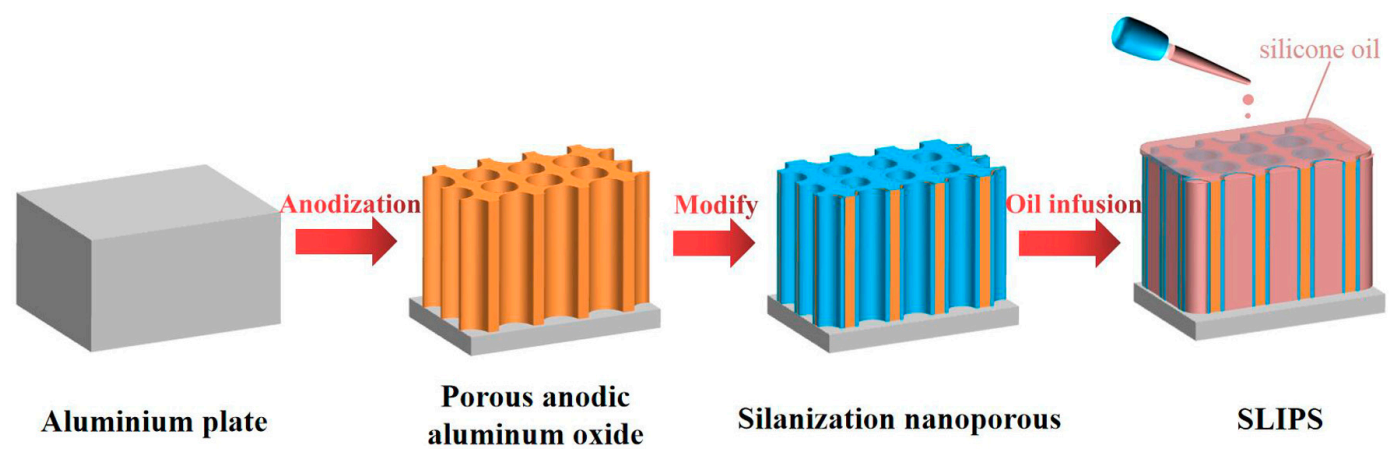

Figure 1. Process diagram for the fabrication of slippery lubricant-infused porous surfaces (SLIPSs).

\subsection{Characterization}

The micromorphology and elementary composition on the surface were examined using a scanning electron microscope (SEM, Zeiss Auriga, Oberkochen, Germany) with attached energy-dispersive X-ray spectroscopy (EDS) (Zeiss Auriga, Oberkochen, Germany). The thermogravimetric analysis (TG) for the silicone oil was performed on a TGA/DSC thermal analyzer (STA 449C, Netzsch, Bavaria, Germany) with a heating rate of $2{ }^{\circ} \mathrm{C} / \mathrm{min}$ from 25 to $300^{\circ} \mathrm{C}$, maintained at $90^{\circ} \mathrm{C}$ for $1 \mathrm{~h}$. The contact angle (CA) of the samples was tested using a contact angle meter (DropMeter A-100, Shanghai, China).

\subsection{Ice Adhesion Test}

The ice adhesion strength of the SLIPS was tested using an ice adhesion test platform. The device consisted of a semiconductor refrigerator, a force transducer (Handpi, HP-200, Shenzhen, China), a motion stage, and a plastic cylinder. The samples were attached to the cooling stage. The cylinder was placed on the samples and filled with water $(2 \mathrm{~mL})$. Ice adhesion strength tests were carried out at $-20{ }^{\circ} \mathrm{C}$ for $3 \mathrm{~h}$. Then, the motion stage was moved at a speed of $1 \mathrm{~mm} / \mathrm{s}$ until the cylinder shifted on the sample. We recorded the maximum force value of the force transducer. The ice adhesion strength value $(\tau)$ is calculated by $\tau=F / S$. F is the measured maximum force. $S$ is the area of the ice sample.

\subsection{Durability}

\subsubsection{Icing/De-Icing Cyclic Test}

To evaluate the durability of the as-prepared SLIPS, a repetitive icing/de-icing test was conducted. The test procedures were similar to the ice adhesion test. The cylinder was placed on the testing samples and filled with $2 \mathrm{~mL}$ of water. The cooling stage was carried out at $-20{ }^{\circ} \mathrm{C}$ for $3 \mathrm{~h}$. The ice cylinder was detached from the samples. We recorded the maximum force value of the force transducer. The samples were heated using a heat gun for every icing/de-icing test.

\subsubsection{Thermal Durability Test}

To confirm the sustainability of the silicone oil within the porous structure surface, the thermal stability of the SLIPS was tested using a dryer at $90^{\circ} \mathrm{C}$ for $168 \mathrm{~h}$. The ice adhesion strength of the SLIPS was tested at different time intervals. 


\section{Results and Discussion}

\subsection{Morphology and Composition}

Figure 2 shows the scanning electron microscope (SEM) images of the AAO layers with pore sizes $(\phi=88 \mathrm{~nm})$ and pore depth $(\mathrm{t}=20 \mu \mathrm{m})$. The SEM images reveal that the well-ordered and uniform nanopore structures were successfully prepared by anodizing. Figure 3 illustrates the SEM images and EDS spectra of the cross-sections of the AAO layers before and after imbibition of the silicone oil. In the case of the AAO with no oil impregnation, the content of silicon was very low. When the $200 \mathrm{mPa} \cdot \mathrm{s}$ silicone oil was impregnated in the AAO pores, the content of silicon increased from $0.6 \%$ to $5.0 \%$, as shown in Figure 3c. Meanwhile, the EDS chemical-element mapping images in the inset in Figure $3 b$ indicate that the distribution of silicon was relatively uniform in the cross-section of the nanoporous structure. The EDS spectra results showed that the $200 \mathrm{mPa} \cdot \mathrm{s}$ silicone oil fully penetrated into the pores. Moreover, the lower viscosity silicone oils produced a more favorable infusion [31]. These results demonstrate that the silicone oil with various viscosities fully infused into the AAO pores. Figure 4 shows the CA of bare Al and the SLIPS filled with various viscosities of silicone oil. The CA result shows that the SLIPS filled with $50 \mathrm{mPa} \cdot \mathrm{s}$ of silicone oil exhibited the largest CA $\left(100.5^{\circ}\right)$, which is larger than that of bare $\mathrm{Al}\left(69.1^{\circ}\right)$.
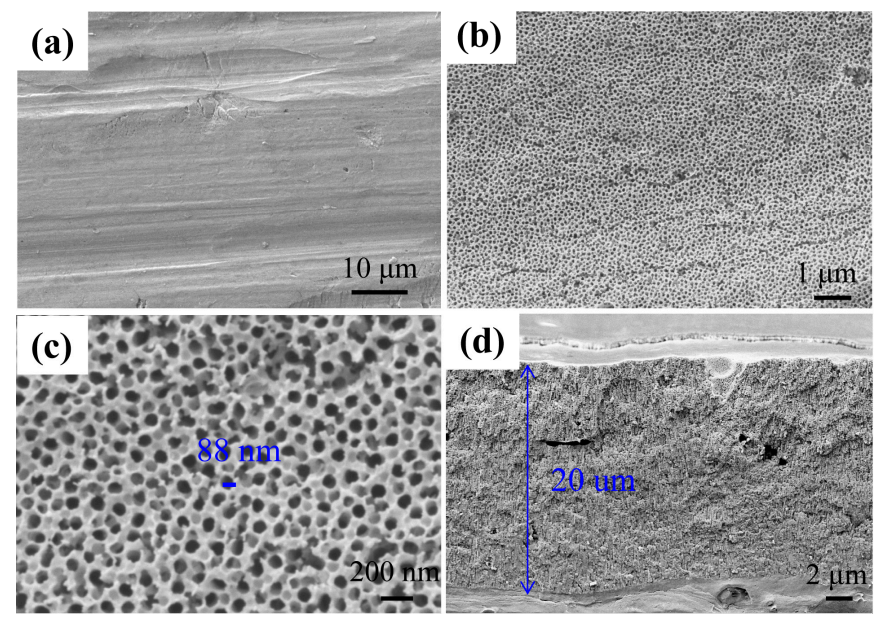

(d)

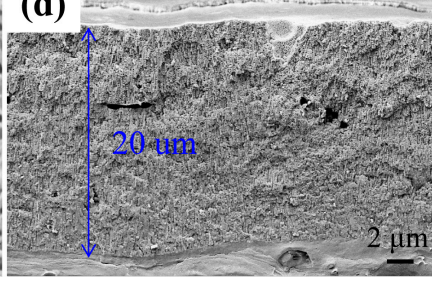

Figure 2. Scanning electron microscope (SEM) images: (a) bare aluminum, (b,c) top view, and (d) cross-section of anodic aluminum oxide (AAO).
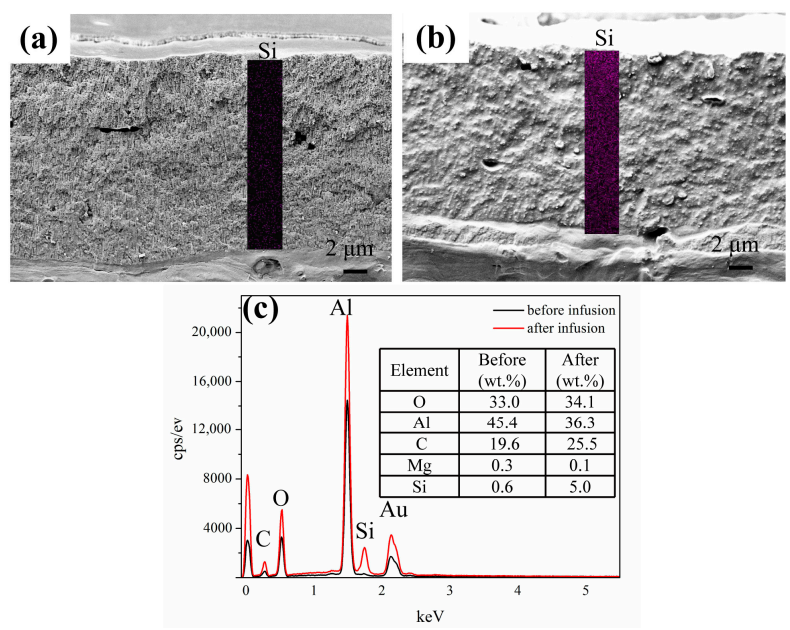

Figure 3. Cross-section of AAO before (a) and after (b) infusion of the silicone oil. The inset shows the EDS mapping images of silicon. (c) EDS spectra of the cross-section of AAO before and after infusion of $200 \mathrm{mPa} \cdot \mathrm{s}$ silicone oil. 

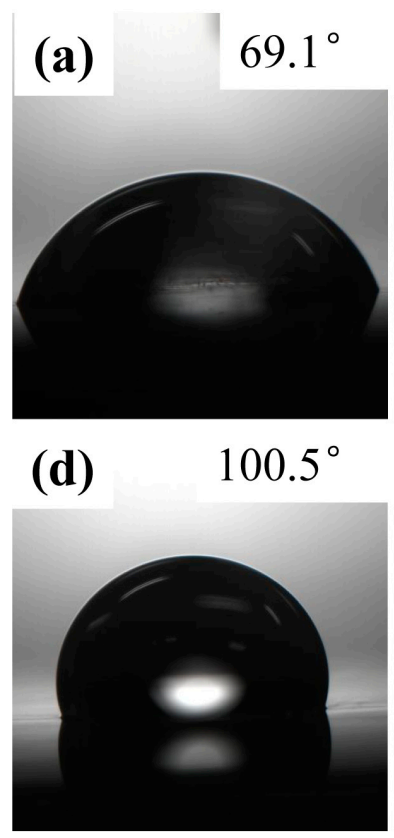

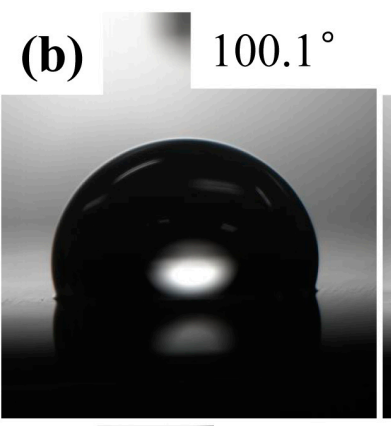

(e)

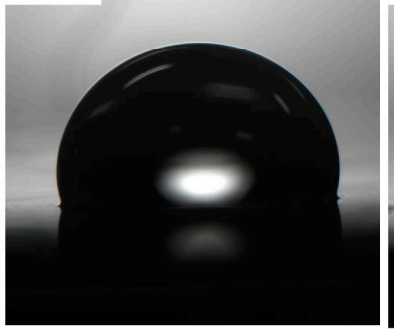

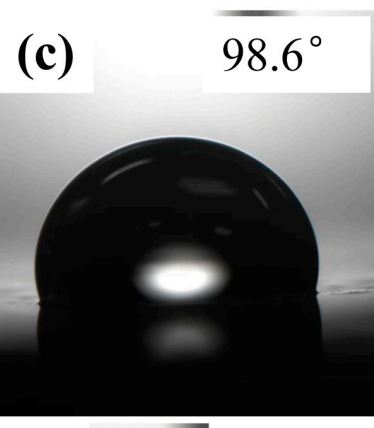

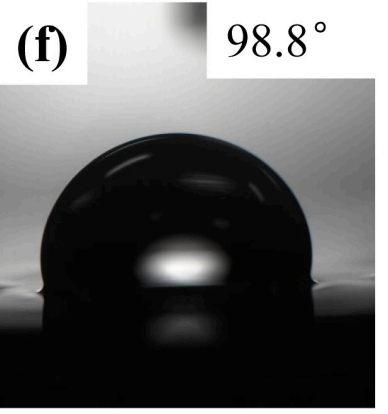

Figure 4. Contact angle of bare $\mathrm{Al}(\mathbf{a})$ and the SLIPS filled with $10 \mathrm{mPa} \cdot \mathrm{s}(\mathbf{b}), 20 \mathrm{mPa} \cdot \mathrm{s}(\mathbf{c}), 50 \mathrm{mPa} \cdot \mathrm{s}(\mathbf{d})$, $100 \mathrm{mPa} \cdot \mathrm{s}(\mathbf{e})$, and $200 \mathrm{mPa} \cdot \mathrm{s}(\mathbf{f})$ of silicone oil.

\subsection{Slippery Properties}

Silicone oil with different viscosities $(10,20,50,100,200 \mathrm{mPa} \cdot \mathrm{s})$ was used for the infusion of AAO surfaces. The sliding angles (SAs) and sliding speed are illustrated in Figure 5. The lowest viscosity silicone oil used $(10 \mathrm{mPa} \cdot \mathrm{s})$ produces outstanding slippery properties, with low water sliding angle values $\left(0.8^{\circ}\right)$ and high sliding velocity $(25 \mathrm{~mm} / \mathrm{s})$. As shown in Figure 4 , the sliding angles of water droplets on the SLIPS increase with increasing silicone oil viscosity. The sliding velocities of droplets on the SLIPS fall when the silicone oil viscosity increases. The results demonstrate that the slippery properties of the SLIPS decrease as the viscosity of silicone oil rises, which is in agreement with the previous study [28]. When droplets slide on the SLIPS, the silicone oil layer is deformed. The high-viscosity silicone oil exhibits a more solid-like character, as a result of which deformation becomes difficult and a large viscous drag is exerted on the sliding of the water. This in turn brings about a growth in the SA, consequently reducing the sliding velocity $[17,28]$.

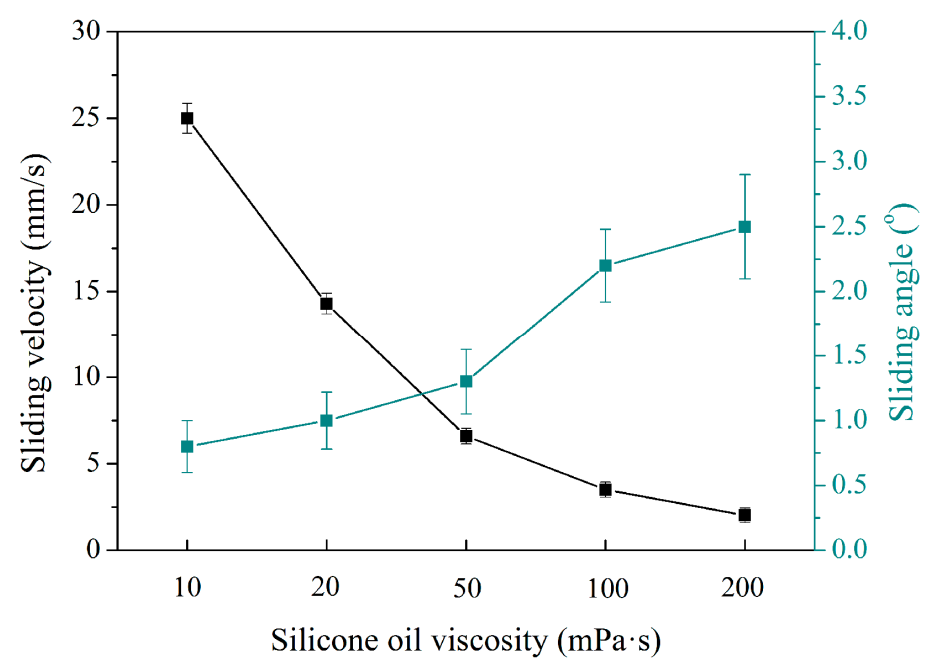

Figure 5. The sliding angles and sliding velocities of the SLIPSs filled with various viscosities of silicone oil. 


\subsection{Ice Adhesion Test}

The ice adhesion strength of bare aluminum coated with different viscosities of silicone oil and of different viscosities of silicone oil-infused porous AAO is shown in Figure 6. The bare aluminum surface exhibits the highest ice adhesion strength of $398 \mathrm{kPa}$. The ice adhesion strength decreases for bare $\mathrm{Al}$ coated with different viscosities of silicone oil compared to the bare aluminum surface, which indicates that an outer layer lubricant is necessary to reduce ice adhesion. In addition, ice adhesion strength increases with the increase of the oil viscosity. A similar trend is observed when the silicone oil infused the porous AAO surfaces. However, the silicone oil-infused porous AAO surfaces exhibit dramatically low ice adhesion strength. The bare aluminum coated with $10 \mathrm{mPa} \cdot \mathrm{s}$ of silicone oil has an ice adhesion strength of $51.4 \mathrm{kPa}$, which drops to $2.7 \mathrm{kPa}$ after the $10 \mathrm{mPa} \cdot \mathrm{s}$ silicone oil is infused into the porous AAO surfaces. The ice adhesion strength is reduced by $99.3 \%$ in contrast with the bare $\mathrm{Al}$ alloy. These results indicate that the porous structures play a vital role in the anti-icing property even if the outermost layer on the surface is the same as a silicone oil. The as-prepared surface with excess lubricant infusing into their pores results in the liquid layer on the top [30,31]. This liquid lubricant layer possesses high mobility, as a result of which the ice can easily detach from the surfaces.

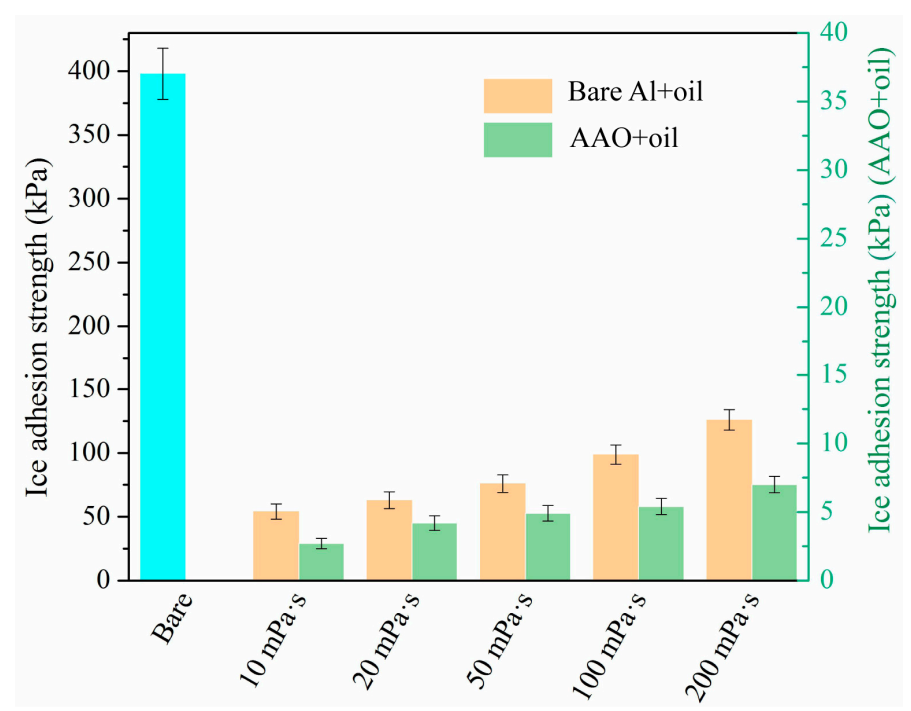

Figure 6. Ice adhesion strength of the various viscosities (10-200 $\mathrm{mPa} \cdot \mathrm{s})$ of silicone oil infused with bare $\mathrm{Al}$ and nanoporous $\mathrm{AAO}$.

\subsection{Durability}

To evaluate icing durability, cyclic icing/de-icing tests were conducted on SLIPS samples. In this test, the ice was accreted and detached 21 times from the SLIPS. As shown in Figure 7, ice adhesion values for all SLIPSs remain below $10 \mathrm{kPa}$ for 6 de-icing cycles. Note that the ice adhesion strength increases much faster on the $10 \mathrm{mPa} \cdot \mathrm{s}$ sample than on the other samples after 12 de-icing tests. Furthermore, we notice that the ice adhesion strength decreases with further tests. When using high-viscosity silicone oil (100, $200 \mathrm{mPa} \cdot \mathrm{s})$, the SLIPS shows dramatic increases in ice adhesion strength after 21 de-icing tests. The SLIPSs with $20 \mathrm{mPa} \cdot \mathrm{s}$ and $50 \mathrm{mPa} \cdot \mathrm{s}$ viscosities of silicone oil show slower increases with the testing cycles in ice adhesion strength. After 21 cycles of icing/de-icing, ice adhesion values increase in the order of $50 \mathrm{mPa} \cdot \mathrm{s}(21.6 \mathrm{kPa})<10 \mathrm{mPa} \cdot \mathrm{s}(23.9 \mathrm{kPa})<20 \mathrm{mPa} \cdot \mathrm{s}(25.1 \mathrm{kPa})<$ $100 \mathrm{mPa} \cdot \mathrm{s}(43.3 \mathrm{kPa})<200 \mathrm{mPa} \cdot \mathrm{s}(50.7 \mathrm{kPa})$. This may be explained by the agile ability of the different viscosities of the silicone oil. A higher silicone oil viscosity leads to higher internal friction and movement resistance and makes the silicone oil difficult to be separated [17]. For the low-viscosity silicone oil, ice carried away the lubricant easily because of the high mobility, which caused a rapid increase in ice adhesion strength on the SLIPS with $10 \mathrm{mPa} \cdot \mathrm{s}$ silicone oil after 12 de-icing tests. The high viscosities of the silicone oil delay lubricant depletion due to the large viscous drag [31]. 


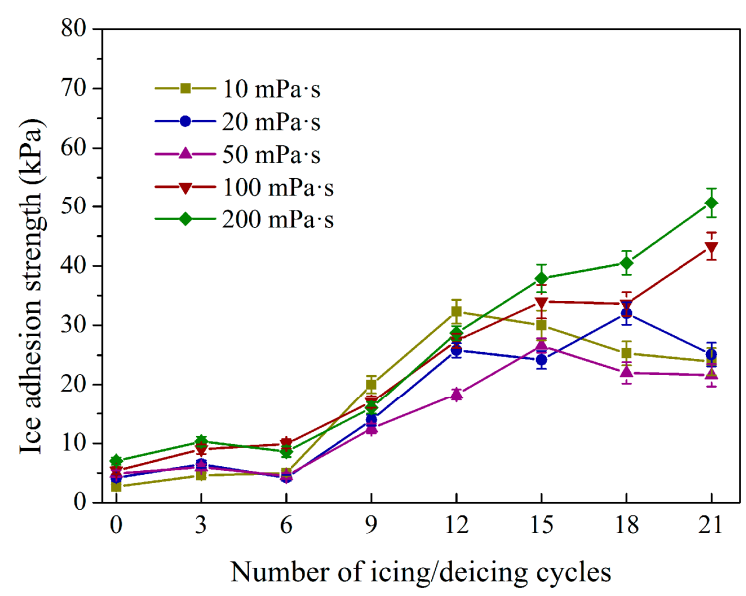

Figure 7. Variation in the ice adhesion strength of the SLIPS filled with different viscosities (10-200 mPa.s) of silicone oil after icing/de-icing cycles.

The slippery properties of the SLIPS were closely connected with the amount of lubricant [31]. The sliding velocities of water droplets on the SLIPS declined due to the loss of silicone oil after icing/de-icing cycles. After 12 de-icing tests, the sliding velocities of droplets on the SLIPS expressed different viscosities of silicone oil, as shown in Figure 8. The sliding velocities of water droplets on the SLIPS with $10 \mathrm{mPa} \cdot \mathrm{s}$ silicone oil decreased from 25 to $1.3 \mathrm{~mm} / \mathrm{s}$. With the increase of viscosities, the sliding velocities reduced slowly. We further explored the effect of viscosity on the self-healing property of the SLIPS by investigating its sliding velocity after exposing the samples to the atmosphere for $3 \mathrm{~h}$. The sliding speed of SLIPS with low-viscosity silicone oil (10,20, $50 \mathrm{mPa} \cdot \mathrm{s})$ increased obviously after exposure. With the increase of viscosities, for the 100 and $200 \mathrm{mPa} \cdot \mathrm{s}$, the sliding velocities increased slowly. These results demonstrate that the viscosity of the silicone oil has a significant effect on the self-healing property. Low-viscosity silicone oil filling in the AAO can enhance the self-healing property of the SLIPS. The lost oil after de-icing can be supplemented by the flow of the top silicone oil layer. Meanwhile, the oil migration from the nanoporous structure to the surface is driven through capillary forces. Low-viscosity silicone oil displays high mobility, and the silicone oil layer can be effectively repaired after de-icing damage, which causes the ice adhesion strength of the SLIPS with $10 \mathrm{mPa} \cdot \mathrm{s}$ silicone oil to decrease after 12 de-icing tests, as shown in Figure 7. For the high-viscosity silicone oil (100 and $200 \mathrm{mPa} \cdot \mathrm{s})$, it was hard for the silicone oil layer to be repaired due to the large viscous drag. Therefore, the SLIPSs with high viscosities of silicone oil (100 and $200 \mathrm{mPa} \cdot \mathrm{s})$ show dramatic increases in ice adhesion strength after 21 de-icing tests.

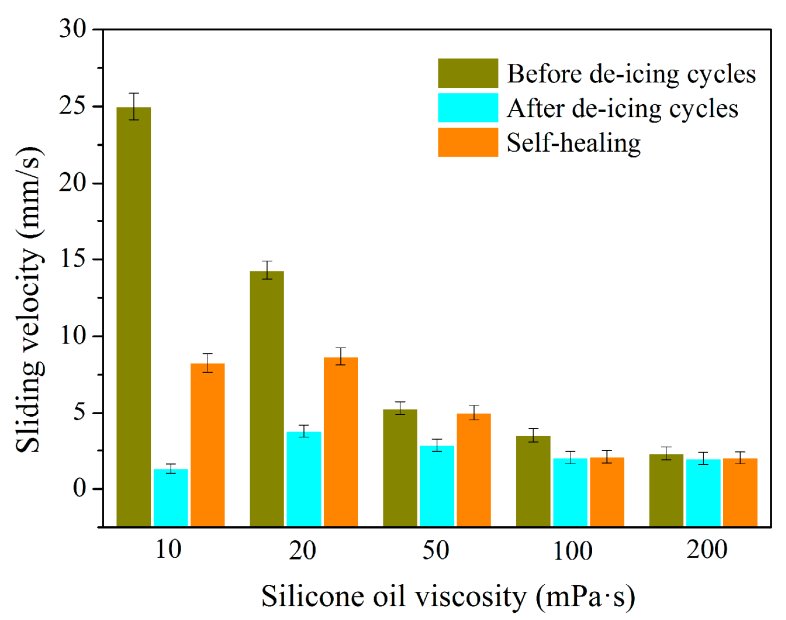

Figure 8. Sliding viscosities of the water droplets $(30 \mu \mathrm{L})$ on the SLIPS with an inclination angle of $\sim 10^{\circ}$ before and after 12 de-icing cycles, then held at room temperature for $3 \mathrm{~h}$. 
The depletion of lubricant due to evaporation can cause a degradation in slippery performance [32,33]. Herein, we tested the thermal durability of SLIPSs via continuous heating at $90{ }^{\circ} \mathrm{C}$. The ice adhesion test was measured after storing for different times. As shown in Figure 9a, the evaporation of silicone oil leads to gradual increases in ice adhesion strength. Note that the ice adhesion strength increased much faster on the $10 \mathrm{mPa} \cdot \mathrm{s}$ sample than on the other samples after $72 \mathrm{~h}$ of heating. When the viscosity of silicone oil was $50 \mathrm{mPa} \cdot \mathrm{s}$, the SLIPS exhibited the better durability for anti-icing. With time prolonged to $168 \mathrm{~h}$, ice adhesion strength values increased in the order of $50 \mathrm{mPa} \cdot \mathrm{s}$ $(20.9 \mathrm{kPa})<20 \mathrm{mPa} \cdot \mathrm{s}(26.4 \mathrm{kPa})<200 \mathrm{mPa} \cdot \mathrm{s}(30.7 \mathrm{kPa})<100 \mathrm{mPa} \cdot \mathrm{s}(32.2 \mathrm{kPa})<10 \mathrm{mPa} \cdot \mathrm{s}(33.0 \mathrm{kPa})$. The results demonstrate that the viscosity of the silicone oil has an obvious effect on the thermal durability. The cause of decreasing ice adhesion with continuous heating was therefore investigated by further thermogravimetric analysis. Figure $9 \mathrm{~b}$ shows the thermogravimetric (mass loss) curves of silicone oil with different viscosities (10-200 mPa.s). During the heating process at $90^{\circ} \mathrm{C}$ for $1 \mathrm{~h}$, some of the silicone oil's (10 and $20 \mathrm{mPa} \cdot \mathrm{s}$ ) weight was lost as volatile matter. The weight loss rate of 10 and $20 \mathrm{mPa} \cdot \mathrm{s}$ was $0.72 \%$ and $0.043 \%$, respectively. There was no obvious change in weight of the high-viscosity silicone oil $(50,100,200 \mathrm{mPa} \cdot \mathrm{s})$. The results suggest that the lower the oil viscosities, the worse the thermal stability. Moderate viscosity silicone oil is required in SLIPSs, as it can delay lubricant depletion to make the SLIPS practical to use.

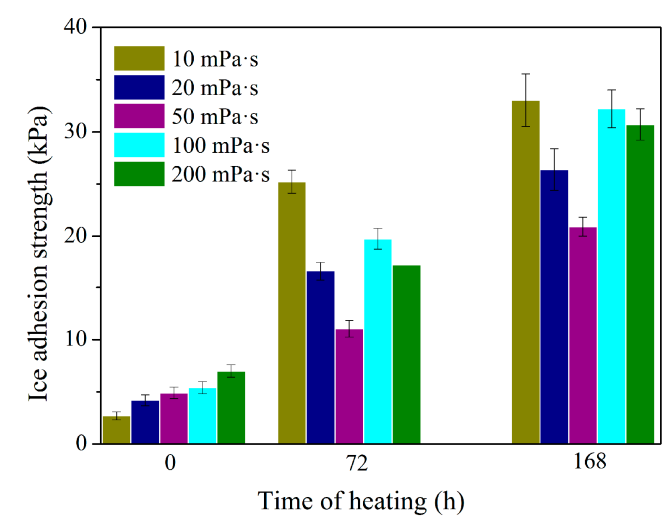

(a)

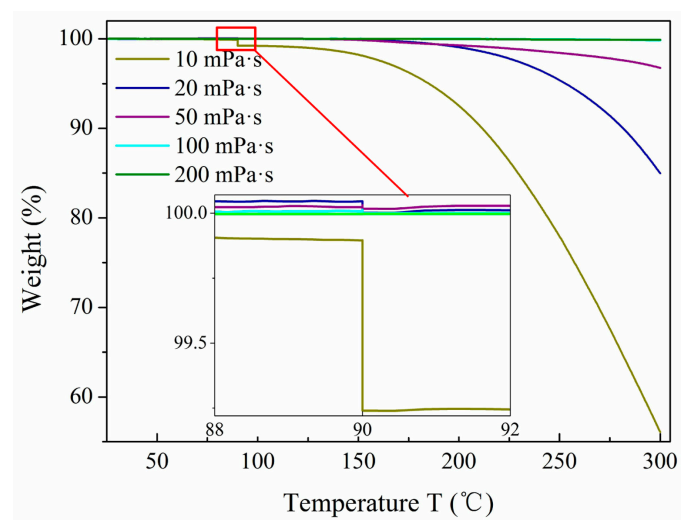

(b)

Figure 9. (a) Variation in the ice adhesion strength of the SLIPS filled with different viscosities (10-200 mPa.s) of silicone oil after the heat-resistant test at $90{ }^{\circ} \mathrm{C}$. (b) Thermogravimetric curve of silicone oil with different viscosities $(10-200 \mathrm{mPa} \cdot \mathrm{s})$. The inset shows the enlarged part marked by the red box.

\section{Conclusions}

In summary, we fabricated a SLIPS with extremely low ice adhesion strength using anodization to form a nanopore structure, modifying the nanopore, and subsequently infusing silicone oil into the 
nanopore. The viscosity of silicone oil affects the ice adhesion strength and durability of the SLIPS. A lower viscosity silicone oil (10 $\mathrm{mPa} \cdot \mathrm{s})$ leads to more slippery surfaces and lower ice adhesion strength $(2.7 \mathrm{kPa})$. A SLIPS with low-viscosity silicone oil has worse de-icing resistance because the silicone oil is easily depleted by icing/de-icing cycles. However, after icing/de-icing cycles and followed by exposure to the atmosphere, low-viscosity silicone oil is beneficial to the recovery of the sliding velocities of water droplets on SLIPSs. The results demonstrate that the lower the oil viscosities, the worse the thermal stability. A moderate viscosity silicone oil is beneficial to maintaining low ice adhesion strength of SLIPSs. When the viscosity of silicone oil is $50 \mathrm{mPa} \cdot \mathrm{s}$, the SLIPS exhibits the best durability for anti-icing. Even after 21 de-icing tests or $168 \mathrm{~h}$ of heating at $90{ }^{\circ} \mathrm{C}$, the ice adhesion strength still remains below $10 \%$ compared with that of bare $\mathrm{Al}$.

Author Contributions: Conceptualization, G.L. and Y.Y.; investigation, G.L., L.W., and X.G.; methodology, G.L. and R.L.; writing — original draft preparation, G.L.; validation, Y.Y. and R.L.; supervision, Y.Y.; writing一review and editing, Y.Y., X.G., and R.L.; funding acquisition, Y.Y. and R.L. All authors have read and agreed to the published version of the manuscript.

Funding: This work was supported by the National Natural Science Foundation of P.R. China (project Nos. 51677015 and 51437001).

Acknowledgments: The authors would like to thank Jia Jiaqi and Hao Longlong from the Electron Microscope Center of Chongqing University.

Conflicts of Interest: The authors declare no conflict of interest.

\section{References}

1. Huneault, M.; Langheit, C.; St.-Arnaud, R.; Benny, J.; Audet, J.; Richard, J.C. A dynamic programming methodology to develop de-icing strategies during ice storms by channeling load currents in transmission networks. IEEE Trans. Power Deliv. 2005, 20, 1604-1610. [CrossRef]

2. Jiang, X.; Fan, C.; Xie, Y. New method of preventing ice disaster in power grid using expanded conductors in heavy icing area. IET Gener. Transm. Distrib. 2019, 12, 536-542. [CrossRef]

3. Wang, J.; Chuang, F.; Yiping, C.; Hong, R.; Shukai, X.; Tao, Y.; Licheng, L. Research and Application of DC De-Icing Technology in China Southern Power Grid. IEEE Trans. Power Deliv. 2012, 27, 1234-1242. [CrossRef]

4. Jiang, X.; Wang, S.; Zhang, Z.; Xie, S.; Wang, Y. Study on AC Flashover Performance and Discharge Process of Polluted and Iced IEC Standard Suspension Insulator String. IEEE Trans. Power Deliv. 2007, 22, 472-480. [CrossRef]

5. Peter, Z.; Farzaneh, M.; Kiss, L.I. Assessment of the Current Intensity for Preventing Ice Accretion on Overhead Conductors. IEEE Trans. Power Deliv. 2006, 22, 565-574. [CrossRef]

6. Zuo, Z.; Song, X.; Liao, R.; Zhao, X.; Yuan, Y. Understanding the anti-icing property of nanostructured superhydrophobic aluminum surface during glaze ice accretion. Int. J. Heat Mass Transf. 2019, 113, 119-128. [CrossRef]

7. Golovin, K.; Dhyani, A.; Thouless, M.D.; Tuteja, A. Low-interfacial toughness materials for effective large-scale deicing. Science 2019, 364, 371-375. [CrossRef]

8. Wong, T.S.; Kang, S.; Tang, S.K.Y.; Smythe, E.; Hatton, B.; Grinthal, A.; Aizenberg, J. Bioinspired self-repairing slippery surfaces with pressure-stable omniphobicity. Nature 2011, 477, 443-447. [CrossRef]

9. Liu, G.; Yuan, Y.; Jiang, Z.; Youdong, J.; Liang, W. Anti-frosting/anti-icing property of nano-ZnO superhydrophobic surface on $\mathrm{Al}$ alloy prepared by radio frequency magnetron sputtering. Mater. Res. Express 2020, 7, 02640117. [CrossRef]

10. Cao, L.; Jones, A.K.; Sikka, V.K.; Wu, J.; Gao, D. Anti-Icing Superhydrophobic Coatings. Langmuir 2009, 25, 12444-12448. [CrossRef]

11. Varanasi, K.K.; Deng, T.; Smith, J.D.; Hsu, M.; Bhate, N. Frost formation and ice adhesion on superhydrophobic surfaces. Appl. Phys. Lett. 2010, 97, 268. [CrossRef]

12. Kulinich, S.A.; Farhadi, S.; Nose, K.; Du, X.W. Superhydrophobic Surfaces: Are They Really Ice-Repellent? Langmuir 2011, 27, 25-29. [CrossRef] [PubMed]

13. Chen, J.; Liu, J.; He, M.; Li, K.; Cui, D.; Zhang, Q.; Zeng, X.; Zhang, Y.; Wang, J.; Song, Y. Superhydrophobic surfaces cannot reduce ice adhesion. Appl. Phys. Lett. 2012, 101, 41-932. [CrossRef] 
14. Golovin, K.; Kobaku, S.P.R.; Lee, D.H.; Diloreto, E.T.; Mabry, J.M.; Tuteja, A. Designing durable icephobic surfaces. Sci. Adv. 2016, 2, e1501496. [CrossRef]

15. Rnneberg, S.; Zhuo, Y.; Laforte, C.; He, J.; Zhang, Z. Interlaboratory Study of Ice Adhesion Using Different Techniques. Coatings 2019, 9, 678. [CrossRef]

16. Li, T.; Zhuo, Y.; Hakonsen, V.; Ronneberg, S.; He, J.; Zhang, Z. Epidermal Gland Inspired Self-Repairing Slippery Lubricant-Infused Porous Coatings with Durable Low Ice Adhesion. Coatings 2019, 9, 602. [CrossRef]

17. Zhang, J.; Wang, A.; Seeger, S. Nepenthes Pitcher Inspired Anti-Wetting Silicone Nanofilaments Coatings: Preparation, Unique Anti-Wetting and Self-Cleaning Behaviors. Adv. Funct. Mater. 2014, 24, 1074-1080. [CrossRef]

18. Lee, J.; Shin, S.; Jiang, Y.; Jeong, C.; Stone, H.A.; Choi, C. Oil-Impregnated Nanoporous Oxide Layer for Corrosion Protection with Self-Healing. Adv. Funct. Mater. 2017, 27, 1606040. [CrossRef]

19. Sun, J.; Wang, C.; Song, J.; Huang, L.; Sun, Y.; Liu, Z.; Zhao, C.; Li, Y. Multi-functional application of oil-infused slippery Al surface: From anti-icing to corrosion resistance. J. Mater. Sci. 2018, 53, 16099-16109. [CrossRef]

20. Kim, P.; Wong, T.S.; Alvarenga, J.; Kreder, M.J.; Adornomartinez, W.E.; Aizenberg, J. Liquid-infused nanostructured surfaces with extreme anti-ice and anti-frost performance. ACS Nano 2012, 6, 6569-6577. [CrossRef]

21. Rykaczewski, K.; Anand, S.; Subramanyam, S.B.; Varanasi, K.K. Mechanism of frost formation on lubricant-impregnated surfaces. Langmuir 2013, 29, 5230-5238. [CrossRef] [PubMed]

22. Kreder, M.J.; Alvarenga, J.; Kim, P.; Aizenberg, J. Design of anti-icing surfaces: Smooth, textured or slippery? Nat. Rev. Mater. 2016, 1, 15003. [CrossRef]

23. Liu, C.; Li, Y.; Lu, C.; Liu, Y.; Liu, Y. Robust Slippery Liquid-Infused Porous Network Surfaces for Enhanced Anti-/De-icing Performance. ACS Appl. Mater. Interfaces 2020, 12, 25471-25477. [CrossRef] [PubMed]

24. Barthwal, S.; Lee, B.; Lim, S.H. Fabrication of robust and durable slippery anti-icing coating on textured superhydrophobic aluminum surfaces with infused silicone oil. Appl. Surf. Sci. 2019, 496, 143677. [CrossRef]

25. Vogel, N.; Belisle, R.A.; Hatton, B.; Wong, T.-S.; Aizenberg, J. Transparency and damage tolerance of patternable omniphobic lubricated surfaces based on inverse colloidal monolayers. Nat. Commun. 2013, 4, 1-10. [CrossRef]

26. Coady, M.J.; Wood, M.; Wallace, G.Q.; Nielsen, K.E.; Kietzig, A.M.; Lagugné-Labarthet, F.; Ragogna, P.J. Icephobic Behavior of UV-Cured Polymer Networks Incorporated into Slippery Lubricant-Infused Porous Surfaces: Improving SLIPS Durability. ACS Appl. Mater. Interfaces 2017, 10, 2890-2896. [CrossRef]

27. Yeong, Y.H.; Wang, C.; Wynne, K.J.; Gupta, M.C. Oil-infused superhydrophobic silicone material for low ice adhesion with long-term infusion stability. ACS Appl. Mater. Interfaces 2016, 8, 32050-32059. [CrossRef]

28. Wang, Z.; Heng, L.; Jiang, L. Effect of lubricant viscosity on the self-healing properties and electrically driven sliding of droplets on anisotropic slippery surfaces. J. Mater. Chem. A 2018, 6, 3414. [CrossRef]

29. Villegas, M.; Zhang, Y.; Abu Jarad, N.; Soleymani, L.; Didar, T.F. Liquid-Infused Surfaces: A Review of Theory, Design, and Applications. ACS Nano 2019, 13, 8517-8536. [CrossRef]

30. Thanh-Binh, N.; Seungchul, P.; Youngdo, J.; Hyuneui, L. Effects of hydrophobicity and lubricant characteristics on anti-icing performance of slippery lubricant-infused porous surfaces. J. Ind. Eng. Chem. 2018, 69, 99-105.

31. Tonelli, M.; Peppou-Chapman, S.; Ridi, F.; Neto, C. Effect of Pore Size, Lubricant Viscosity, and Distribution on the Slippery Properties of Infused Cement Surfaces. J. Phys. Chem. C 2019, 123, 2987-2995. [CrossRef]

32. Baumli, P.; Teisala, H.; Bauer, H.; Garcia-Gonzalez, D.; Damle, V.; Geyer, F.; D'Acunzi, M.; Kaltbeitzel, A.; Butt, H.R.; Vollmer, D. Flow-Induced Long-Term Stable Slippery Surfaces. Adv. Sci. 2019, 6, 1900019. [CrossRef] [PubMed]

33. Zhou, W.; Zeng, Y.; Liu, B.; Yu, S.; Hua, W.; Huang, X. Evaporation of polydisperse perfluoropolyether lubricants in heat-assisted magnetic recording. Appl. Phys. Express 2011, 4, 544-548. [CrossRef]

(C) 2020 by the authors. Licensee MDPI, Basel, Switzerland. This article is an open access article distributed under the terms and conditions of the Creative Commons Attribution (CC BY) license (http://creativecommons.org/licenses/by/4.0/). 